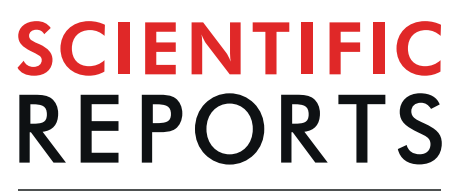

natureresearch

\title{
Associations of ACE I/D polymorphism with the levels of ACE, kallikrein, angiotensin II and interleukin-6 in STEMI patients
}

\author{
Shuhong Dai ${ }^{1}$, Mei Ding ${ }^{2}$, Na Liang ${ }^{3}$, Zhuo Li ${ }^{4}$, Daqing Li ${ }^{5}$, Lianyue Guan ${ }^{6 *}$ \& Hongyu Liu ${ }^{6 *}$
}

This study aimed to compare the plasma levels of angiotensin-I converting enzyme (ACE), Angiotensin II (Angll), kallikrein (KLK1) and interleukin-6 (IL-6) in ST segment elevation myocardial infarction (STEMI) patients with different ACE Insertion/deletion (I/D) polymorphisms in a Chinese population. The ACE genotypes were determined in the 199 STEMI patients and 216 control subjects. STEMI patients were divided into three groups based on the ACE genotypes. Single polymerase chain reaction (PCR) was performed to characterize ACE I/D polymorphisms. Plasma levels of ACE, Angll, KLK1 and IL-6 were measured by enzyme-linked immunosorbent assay (ELISA). We found that the DD or ID genotype was significantly independently associated with high $\mathrm{ACE}(\mathrm{OR}=4.697 ; 95 \% \mathrm{Cl}=1.927-11.339)$, $\mathrm{KLK1}$ (3.339; $1.383-8.063)$ and IL-6 levels (OR $=2.10 ; 1.025-4.327)$ in STEMI patients. However, there was no statistical significance between the ACE I/D polymorphism and Angll plasma levels whether in univariate or multivariate logistic regression. Additionally, we detected a significantly positive correlation between plasma KLK1 levels and IL- 6 levels in STEMI patients $(r=0.584, P<0.001)$. The study showed high levels of ACE, KLK1 and IL- 6 were detected when the $D$ allele was present, but Angll plasma levels was not influenced by the $A C E \mathrm{I} / \mathrm{D}$ polymorphism.

Acute myocardial infarction (AMI) is a major cause of morbidity and mortality worldwide, and it has been estimated that approximately $50 \%$ to $60 \%$ of the major risk factors for CAD and AMI are determined by heritability ${ }^{1}$. The ST segment elevation myocardial infarction (STEMI) is one of the most severe types of AMI. It primarily occurs due to the rupture of atherosclerotic plaques. A human angiotensin I-converting enzyme (ACE) gene insertion/deletion (I/D) polymorphism, due to I/D of a 287-base pair element in intron 16 of this gene, is associated with the development of AMI by modifying ACE activity and contributing to enhanced plaque vulnerability, ulceration and thrombosis ${ }^{2,3}$. Our recent case-control study has also demonstrated that the ACE DD genotype is an independent risk factor for STEMI ${ }^{4}$.

ACE, an important common regulator of the Kallikrein-Kinin system (KKs) and the rein-angiotensin system (RAs), was revealed to convert angiotensin (AngI) into angiotensin II (AngII) and inactivate bradykinin (BK). ACE plays an important role in the physiology of blood vessels and inflammatory processes and has been widely studied to observe its correlation with various cardiovascular diseases ${ }^{3}$. There is substantial evidence that the ACE I/D polymorphism determines ACE, which has been demonstrated by the mean plasma ACE concentrations in individuals with the DD genotype being approximately twice that in II individuals, with ID individuals having intermediate concentrations ${ }^{5}$.

Among the different roles of AngII, this protein enhances the levels of cytokines, such as interleukin-6(IL-6) and IL-8, thus playing a proinflammatory role $^{6}$. Kallikrein (KLK1), which is responsible for the generation of $\mathrm{BK}$, stimulated the proinflammatory cytokines IL-6 and IL-8, as another novel action of its contribution to

${ }^{1}$ Department of Cardiology, Zibo Central Hospital, Shandong University, No.54, Gong Qing Tuan Xi Road, Zibo, 255036, Shandong, China. ' Department of Cardiology, China-Japan Union Hospital of Jilin University, Changchun, 130033, Jilin, China. ${ }^{3}$ Office of Surgical Nursing Changchun Medical College, Changchun, Jilin, China. ${ }^{4}$ Department of Emergency, Hospital of Weifang Medical College, Weifang, Shandong, China. ${ }^{5}$ Department of Cardiology, Qilu Hospital, Shandong University, Jinan, Shandong, China. ${ }^{6}$ Department of Hepatobiliary-Pancreatic Surgery, China-Japan Union Hospital of Jilin University, Changchun, 130033, Jilin, China. *email: 13504310464@163.com; yuhongliu0101@163.com 
neovascularization ${ }^{7,8}$. Both inflammation and neovascularization have been reported to enhance plaque vulnerability ${ }^{9}$. Animal models and clinical studies demonstrated that ACE, AngII, KLK1 and IL-6 were highly expressed in unstable plaques and were significantly increased in ACS (acute coronary artery syndrome) patients ${ }^{10,11}$. Additionally, previous studies have shown interactions between RAs, KKs and inflammation ${ }^{12,13}$. In this context, we hypothesized that changes in ACE activity through the ACE I/D polymorphism may result in an increase in vasoactive members associated with the RAs, KKs and inflammation, such as AngII, KLK1 and IL-6. Changes in AngII, KLK1 and IL-6 levels could possibly depend on the range of ACE activity differences between the ACE I/D genotypes. To date, the association of ACE genetic polymorphisms with changes in ACE, AngII, KLK1 and IL-6 plasma levels has not been investigated in patients with STEMI.

The aim of the present study was to determine the possible interplay between the ACE I/D polymorphism and the important vasoactive substance of the RAs ACE, AngII, the important regulator of the KKs KLK1, and the inflammatory mediator IL-6 in patients with STEMI in the Chinese population.

\section{Methods}

Subjects. All procedures in studies involving human participants were performed in accordance with the ethical standards of the institutional or national research committee and with the 1964 Declaration of Helsinki and its later amendments or comparable ethical standards. This study was approved by the Ethics Committee of the Central Hospital of Zibo (approval no. ZBH05485). Informed consent for participation was obtained from all patients and their parents in an appropriate manner. A total of 260 STEMI patients admitted to the Central Hospital of Zibo from January 2014 to January 2017 and diagnosed with STEMI undergoing coronary angiography (CAG) were enrolled. All patients met the inclusion criteria, including an electrocardiography showing STEMI, detection of an increase and or decrease in troponin I with at least 1 value more than the 99th percentile upper reference limit, and at least 1 of the following: myocardial ischemic symptoms lasting longer than 30 minutes; electrocardiogram changes indicative of new ischemia (ST-segment elevation $>2 \mathrm{~mm}$ in 2 contiguous ECG leads within 24 hours of the onset of symptoms). In addition, the CAG results for the subjects showed the presence of an acute occlusion in at least one major coronary vessel or one of its major branches. Control subjects $(\mathrm{N}=216)$ had no clinical evidence of CAD, including (1) negative CAG examination results, (2) no abnormal Q wave or ST-T changes found in the resting electrocardiogram and no abnormalities found on cardiac ultrasound examinations, and (3) a negative Master exercise test. The exclusion criteria for the STEMI patients and control group were as follows: severe renal failure (serum creatinine $>180 \mathrm{mmol} / \mathrm{l}$ ), severe hepatic disease, peripheral angiopathy, malignant cancer and serious infections. Patients treated with ACEIs were also excluded because ACEI medication ( $>1$ month) may affect the levels of ACE, AngII, KLK1 and IL-6 ${ }^{14,15}$. Finally, a total of 199 patients (51 female and 148 male) with STEMI were included in this study, and 61 patients were excluded. The control subjects constituted 96 female and 120 male.

Data collection and blood sampling. All data collection was performed with quality control. Anthropometric data on age, sex, body weight, BMI [weight $\left(\mathrm{m}^{2}\right) /$ height $(\mathrm{kg})$ ], SBP, DBP, a smoking habit (one pack year: $\geq 20$ cigarettes per day for more than 1 year), and comorbid conditions. The diagnosis of hypertension and diabetes mellitus was performed according to World Health Organization criteria A smoking habit was defined as a daily intake of $>10$ cigarettes continuing for more than 1 year. The other criteria are consistent with a previous study ${ }^{4}$. The fasting blood samples tested for routine blood, lipid profiles and coagulation tests were routinely performed in the hospital laboratory.

Fifteen milliliters of blood were taken from the arterial sheath access of all subjects during CAG prior to the injection of contrast. Blood samples were collected in tubes containing ethylene diamine tetraacetic acid (EDTA) and aprotinin and were separated by centrifugation at $4{ }^{\circ} \mathrm{C}$ for 10 minutes at $3000 \mathrm{rpm}$ within one hour after collection. Then, the plasma used to measure ACE, AngII, KLK1, and IL-6 levels and leukocytes used for DNA extraction from arterial blood (during CAG). These were separated and stored at $-80^{\circ} \mathrm{C}$ until assayed.

Coronary angiography (CAG). The standard Judkins technique was implemented for coronary angiography (CAG). CAG was performed on the basis of standards of clinical practice using contrast agents (iodine amine (370)). Then, we examined the left main trunk (LM), the left anterior descending artery (LAD), the left circumflex artery (LCX), and the right coronary artery (RCA) and evaluated the stenosis of coronary arteries. Two independent and experienced interventional cardiologists blinded to the clinical information for the subjects performed the angiographic assessment.

Measurements of ACE, Angll, KLK1 and IL-6. Plasma levels of ACE, AngII, KLK1 and IL-6 were measured by enzyme-linked immunosorbent assay (ELISA) using commercially available kits (Lengton Bioscience Co., Ltd., Shanghai; LOT: 201500506MY), which were based on a competitive enzyme immunoassay technique.

Human ACE, AngII, KLK1 and IL-6 levels in plasma were measured in strict accordance with the manufacturer's instructions, as described previously ${ }^{4}$. Briefly, polyclonal antibodies specific for these three proteins were precoated onto 96 -well plates and incubated for 24 hours at $4^{\circ} \mathrm{C}$. The plasma samples and horseradish peroxidase (HRP) antigen were added to each well. Standards, samples and avidin conjugated to horseradish peroxidase (HRP) were then added to the appropriate microplate wells. After rocking, the plates were covered with sealing film and incubated at $37^{\circ} \mathrm{C}$ for $1 \mathrm{~h}$. The plates were repeatedly washed 3 times with $1 \%$ BSA-PBS. Then, TMB substrate solution was added to each well and incubated at $37^{\circ} \mathrm{C}$ for $10 \mathrm{~min}$ without light. After $10 \mathrm{~min}$, the enzyme substrate reaction was terminated by the addition of a sulfuric acid solution. Subsequently, the optical density (OD) was measured with a Bio-Rad ELISA plate reader (Infinite M200Pro, TECAN) at a wavelength of $450 \mathrm{~nm}$. The plasma levels of ACE, AngII, KLK1 and IL-6 in the samples were obtained by comparison with a calibrated standard curve. 


\begin{tabular}{|c|c|c|c|c|c|c|}
\hline \multirow[b]{2}{*}{ Parameters } & \multirow{2}{*}{\begin{tabular}{|l|} 
STEMI \\
$(\mathrm{n}=199)$ \\
\end{tabular}} & \multirow{2}{*}{\begin{tabular}{|l|} 
Control \\
$(n=216)$ \\
\end{tabular}} & \multirow{2}{*}{\begin{tabular}{|l|} 
Univariate \\
OR $(\mathbf{9 5} \% \mathrm{CI})$ \\
\end{tabular}} & \multirow[b]{2}{*}{$\mathbf{p}^{*}$} & \multirow{2}{*}{\begin{tabular}{|l|} 
Multivariate \\
OR $(\mathbf{9 5} \% \mathrm{CI})$ \\
\end{tabular}} & \multirow[b]{2}{*}{$\mathbf{p}^{*}$} \\
\hline & & & & & & \\
\hline \multicolumn{7}{|l|}{ ACE genotypes } \\
\hline II & 65 & 88 & 1 (ref.) & & 1 (ref.) & \\
\hline ID & 89 & 108 & $1.167(0.764-1.783)$ & 0.474 & $1.167(0.764-1.783)$ & 0.474 \\
\hline $\mathrm{DD}$ & 45 & 20 & $3.654(1.932-6.911)$ & $<0.001$ & $5.585(2.459-12.685)$ & $<0.001$ \\
\hline Age (year) $<60$ & 95 & 136 & 1 (ref.) & & 1 (ref.) & \\
\hline$\geq 60$ & 104 & 80 & $1.921(1.303-2.832)$ & 0.001 & $0.830(0.078-2.104)$ & 0.159 \\
\hline BMI $\left(\mathrm{kg} / \mathrm{m}^{2}\right)<27$ & 82 & 45 & 1 (ref.) & & & \\
\hline$\geq 27$ & 117 & 172 & $1.645(0.980-2.760)$ & 0.060 & & \\
\hline Gender-Female & 51 & 96 & 1 (ref.) & & & \\
\hline Male & 148 & 120 & $0.431(0.284-0.653)$ & 0.071 & & \\
\hline Hypertension-No & 108 & 132 & 1 (ref.) & & & \\
\hline Yes & 91 & 84 & $1.324(0.896-1.957)$ & 0.159 & & \\
\hline Diabetes-No & 162 & 200 & 1 (ref.) & & 1 (ref.) & \\
\hline Yes & 37 & 16 & $3.553(1.838-6.876)$ & $<0.001$ & $2.081(0.089-8.432)$ & 0.076 \\
\hline Smoking-No & 79 & 156 & 1 (ref.) & & 1 (ref.) & \\
\hline Yes & 116 & 60 & 3.230 (2.146-4.859) & $<0.001$ & 3.570 (2.079-6.132) & $<0.001$ \\
\hline WBC $\left(10^{9} / \mathrm{l}\right)$ & $9.1 \pm 0.1$ & $10.2 \pm 1.1$ & $0.525(0.111-1.022)$ & 0.081 & & \\
\hline HDL-c (mmol/l) & $1.1 \pm 0.2$ & $1.3 \pm 0.4$ & $0.209(0.101-0.430)$ & 0.058 & & \\
\hline FIB $(\mathrm{mmol} / \mathrm{l})$ & $3.2 \pm 0.7$ & $3.3 \pm 0.1$ & $0.929(0.710-1.271)$ & 0.595 & & \\
\hline
\end{tabular}

Table 1. Univariate and multivariate analyses of STEMI risk factors. STEMI: acute coronary syndrome, ACE: angiotensin converting enzyme, BMI: body mass index, WBC: white blood count, HDL-c: high density lipoprotein cholesterol, FIB: plasma fibrinogen, CI: confidence interval; OR: odds ratio. On the basis of logistic regression, statistical significance $(\mathrm{p}<0.05)$ is shown in bold.

Detection of the ACE polymorphism. Genomic DNA was extracted from arterial blood (during CAG) using a human genome extraction kit (purchased from TIANGEN Biotechnology Co., LTD). The DNA concentration was measured at $260 \mathrm{~nm}$, and quality controls were conducted. ACE I/D polymorphisms were determined by polymerase chain reaction (PCR). The primers had the following sequences: $5^{\prime}$-CTG GAG ACC ACT CCC ATC CTT CT-3' (forward primer) and 5'-GAT GTG GCC ATC ACA TTC GTC AGA T-3' (reverse primer). To eliminate the potential that the D allele of the ACE gene was overestimated due to failure to amplify the I allele, all DD genotype samples were confirmed by another pair of insertion-specific primers: forward, $5^{\prime}$-TCG GAC CAC AGC GCC CGC CAC TAC-3'; and reverse, $5^{\prime}$-TCG CCA GCC CTC CCA TGC CCA TAA- $3^{\prime}$. The DNA was amplified for $30 \mathrm{cycles}$, including denaturation at $94^{\circ} \mathrm{C}$ for 1 minute, annealing at $55^{\circ} \mathrm{C}$ for $30 \mathrm{~s}$ and extension at $72^{\circ} \mathrm{C}$ for $10 \mathrm{~min}$. Then, $10 \mu \mathrm{l}$ of the amplified product was examined by $1.5 \%$ agarose gel electrophoresis. PCR amplification produced fragments of $490 \mathrm{bp}$, indicating the I allele, and $190 \mathrm{bp}$, indicating the $\mathrm{D}$ allele, thus yielding genotypes II, ID and DD, respectively. An additional $335 \mathrm{bp}$ product, a consequence of PCR using a pair of insertion-specific primers, also indicted the I allele.

Statistical methods. The data were analyzed by SPSS version 19.0 (SPSS Co., Chicago, IL, USA) for Windows. Hardy-Weinberg equilibrium (HWE) for the distributions of ACE genotypes was performed by the chi square $\left(\chi^{2}\right)$ test. The odds ratios (ORs) and corresponding $95 \%$ confidence intervals (CIs) for assessing the effect of the ACE I/D genotype distribution and allele frequencies on the levels of ACE, AngII, KLK1, and IL-6 in STEMI patients were calculated by logistic regression analysis. The Spearman rank test was used to define the correlation between them. For all the analyses, statistical significance was defined as $\mathrm{P}<0.05$.

\section{Results}

General characteristics and genotype distribution. As shown in Table 1, comparisons of the distributions of demographic general clinical and biochemical characteristics, genotype distribution and the estimated OR for each risk factor are listed. In the univariate logistic regression model, the ACE DD genotype, older age, a history of smoking habits and the presence of diabetes were found to be high risk factors for STEMI. The other variables including hypertension, body mass index (BMI), gender, white blood count (WBC), high-density lipoprotein (HDL) and plasma fibrinogen (FIB) were not significantly different between the two groups.

After adjusting for the other risk factors (age, BMI, Sex, hypertension, diabetes mellitus and smoking habits) the DD genotype was still significantly associated with STEMI, conferring a 5-fold higher risk (OR $=5.585 ; 95 \%$ CI: 2.459-12.685). A history of smoking habits was the only other independent risk factor in multivariate logistic regression, which was in accordance with other studies ${ }^{16}$.

Association of the ACE I/D Polymorphism with the plasma Levels of ACE, KLK1, Angll, IL-6 in STEMI patients. To further evaluate the etiologic effects of ACE I/D polymorphisms in STEMI, we evaluated the possible influence of ACE I/D polymorphisms on STEMI-relevant traditional risk factors, plasma ACE, 


\begin{tabular}{|c|c|c|c|c|c|c|c|c|}
\hline \multirow{3}{*}{$\begin{array}{l}\text { ACE genotypes } \\
\text { Parameters }\end{array}$} & \multicolumn{2}{|l|}{ II $(n=65)$} & \multicolumn{3}{|l|}{ ID $(n=89)$} & \multicolumn{3}{|c|}{$\mathrm{DD}(\mathrm{n}=45)$} \\
\hline & \multirow[b]{2}{*}{$\mathbf{n}$} & & \multirow[b]{2}{*}{$\mathbf{n}$} & \multirow{2}{*}{$\begin{array}{l}\text { Univariate } \\
\text { OR }(95 \% \mathrm{CI})\end{array}$} & \multirow[b]{2}{*}{$\mathbf{p}^{*}$} & \multirow[b]{2}{*}{$\mathbf{n}$} & \multirow{2}{*}{\begin{tabular}{|l|} 
Univariate \\
OR $(95 \% \mathrm{CI})$ \\
\end{tabular}} & \multirow[b]{2}{*}{$\mathbf{p}^{*}$} \\
\hline & & & & & & & & \\
\hline Age (year) $<60$ & 33 & 1 (ref.) & 45 & & & 17 & & \\
\hline$\geq 60$ & 32 & & 44 & $0.983(0.949-1.013)$ & 0.232 & 28 & $1.272(0.574-2.819)$ & 0.553 \\
\hline BMI $\left(\mathrm{kg} / \mathrm{m}^{2}\right)<27$ & 29 & 1 (ref.) & 32 & & & 21 & & \\
\hline$\geq 27$ & 36 & & 57 & $1.435(0.747-2.757)$ & 0.279 & 24 & $0.921(0.429-1.974)$ & 0.832 \\
\hline Gender-Female & 40 & 1 (ref.) & 69 & & & 33 & & \\
\hline Male & 25 & & 20 & $0.464(0.229-0.939)$ & 0.033 & 12 & $0.582(0.254-1.332)$ & 0.200 \\
\hline $\mathrm{SBP}(\mathrm{mmHg})<140$ & 57 & 1 (ref.) & 77 & & & 41 & & \\
\hline$\geq 140$ & 8 & & 12 & $1.110(0.426-2.894)$ & 0.830 & 4 & $0.695(0.196-2.464)$ & 0.573 \\
\hline DBP $(\mathrm{mmHg})<90$ & 33 & 1 (ref.) & 50 & & & 29 & & \\
\hline$\geq 90$ & 32 & & 39 & $8.874(0.263-15.787)$ & 0.129 & 16 & $6.244(0.674-57.842)$ & 0.107 \\
\hline Hypertension-No & 33 & 1 (ref.) & 40 & & & 25 & & \\
\hline Yes & 32 & & 49 & $1.263(0.665-2.398)$ & 0.475 & 20 & $0.569(0.261-1.242)$ & 0.157 \\
\hline Diabetes-No & 52 & 1 (ref.) & 69 & & & 41 & & \\
\hline Yes & 13 & & 20 & $1.159(0.529-2.543)$ & 0.712 & 4 & $0.390(0.118-1.287)$ & 0.122 \\
\hline Smoking-No & 40 & 1 (ref.) & 69 & & & & & \\
\hline Yes & 25 & & 20 & $2.715(1.404-5.250)$ & 0.003 & & $2.635(1.205-5.765)$ & 0.015 \\
\hline WBC $\left(10^{9} / \mathrm{l}\right)$ & $10.1 \pm 3.3$ & 1 (ref.) & $10.3 \pm 2.8$ & $0.944(0.850-1.049)$ & 0.284 & $10.1 \pm 3.1$ & $0.899(0.790-1.022)$ & 0.103 \\
\hline HDL-c $(\mathrm{mmol} / \mathrm{l})$ & $1.1 \pm 0.3$ & 1 (ref.) & $1.1 \pm 0.2$ & $0.379(0.095-1.516)$ & 0.170 & $1.2 \pm 0.2$ & $1.558(0.343-7.073)$ & 0.566 \\
\hline FIB $(\mathrm{mmol} / \mathrm{l})$ & $3.1 \pm 0.54$ & 1 (ref.) & $3.2 \pm 0.7$ & $1.159(0.736-1.825)$ & 0.524 & $3.4 \pm 1.0$ & $1.477(0.874-2.496)$ & 0.145 \\
\hline
\end{tabular}

Table 2. Associations between ACE I/D polymorphisms and clinical characteristics in STEMI patients. BMI: body mass index, SBP: Systolic blood pressure DBP: Diastolic blood pressure, WBC: white blood count, HDLc: high density lipoprotein cholesterol, FIB: plasma fibrinogen. On the basis of logistic regression, statistical significance $(\mathrm{p}<0.05)$ is shown in bold.

AngII, KLK1, and IL-6 levels. For further statistical analysis, the above plasma indicators were divided into high vs. low levels according to the mean of the STEMI patients. As shown in Tables 2 and 3, no obvious association was observed between these clinical and biochemical characteristics (age, BMI, Gender, hypertension, diabetes, WBC, HDL-c and FIB) and the ACE I/D polymorphism. However, the ACE DD and ID genotypes were found to be statistically significant associated in STEMI patients who had smoking habits (OR: 2.635, 95\% CI 1.205-5.765), high plasma ACE levels (5.222; 2.290-11.907), high KLK1 (2.847; 1.277-6.545) and high IL-6 levels (2.100; 1.0254.327) in STEMI patients.

After adjusting for other risk factors, the DD genotype was still significantly independently associated with smoking habits $(\mathrm{OR}=1.123,95 \% \mathrm{CI}$ : 1.041-1.212), high ACE levels (4.697; 1.927-11.339) and high KLK1 levels (3.339; 1.383-8.063) (Table 4). Whereas, there was no statistical significance between the ACE I/D polymorphism and the AngII plasma levels whether in univariate or multivariate logistic regression.

The Spearman correlation coefficient revealed a significant positive correlation between ACE and KLK1 $(\mathrm{r}=0.430, \mathrm{P}=0.038)$, KLK1 and AngII $(\mathrm{r}=0.256, \mathrm{P}<0.001)$, KLK1 and IL-6 $(\mathrm{r}=0.584, \mathrm{P}<0.001)$ in patients with STEMI (Fig. 1).

\section{Discussion}

The ACE DD genotype is a great risk factor for AMI and has been extensively studied. There is substantial evidence showing that the ACE DD genotype may play a key role in the onset of AMI by altering plasma ACE levels or activity and increasing the instability of atherosclerotic plaques2,3. One study found that both Caucasian and Asian individuals as DD carriers conferred 1.21- and 2.47-fold risks of AMI, respectively, compared with ID or II genotype carriers, and Asian individuals as DD carriers appeared to be more prone to AMI than did Caucasian individuals3. This result was also similar to most studies in different populations or study cohorts ${ }^{17,18}$. One recent case-control study also demonstrated that the ACE DD genotype was an independent risk factor for AMI in a Chinese population4. A similar result was also found in the present study. After controlling for other risk factors, the DD genotype was still significantly associated with STEMI, conferring a 5-fold higher risk.

There was a significant increased risk for STEMI among individuals with DD genotypes and smoking habits. A previous study noted that The presence of the $\mathrm{D}$ allele also increased the risk of CAD associated with the presence of smoking habits ${ }^{19}$. Indeed, smoking and the D allele increase ACE expression, impair protective antioxidant mechanisms, causing endothelial dysfunction by accelerating superoxide anion formation and degradation of nitric oxide, leading to the onset of STEMI ${ }^{19-21}$. Our results showed that both the DD genotype and smoking habits were associated with an increased risk of STEMI in patients. Our study demonstrated that there may be an association between the DD or ID genotype and smoking in patients with STEMI $(\mathrm{OR}=1.123,95 \%$ CI: 1.041-1.212). As Kiyoshi Hibi et al. suggested that ACE gene polymorphism adds risk for the severity of coronary atherosclerosis in smokers ${ }^{22}$.

Previous studies have shown that subjects with the D polymorphism had a higher level of plasma ACE protein than did those with the I polymorphism. Intermediate levels were observed in heterozygotes (ID genotype) ${ }^{5}$. 


\begin{tabular}{|c|c|c|c|c|c|c|c|c|}
\hline \multirow{3}{*}{$\begin{array}{l}\text { ACE genotypes } \\
\text { Parameters }\end{array}$} & \multicolumn{2}{|c|}{ II $(n=65)$} & \multicolumn{3}{|c|}{ ID $(n=89)$} & \multicolumn{3}{|c|}{$\mathrm{DD}(\mathrm{n}=45)$} \\
\hline & \multirow[b]{2}{*}{$\mathbf{n}$} & & \multirow[b]{2}{*}{$\mathbf{n}$} & \multirow{2}{*}{$\begin{array}{l}\text { Univariate } \\
\text { OR }(95 \% \mathrm{CI})\end{array}$} & \multirow[b]{2}{*}{$\mathrm{p}^{*}$} & \multirow[b]{2}{*}{$\mathbf{n}$} & \multirow{2}{*}{$\begin{array}{l}\text { Univariate } \\
\text { OR }(95 \% \mathrm{CI})\end{array}$} & \multirow[b]{2}{*}{$\mathrm{p}^{*}$} \\
\hline & & & & & & & & \\
\hline ACE $(\mathrm{ng} / \mathrm{ml})<174$ & 47 & 1 (ref.) & 47 & & & 15 & & \\
\hline$\geq 174$ & 18 & & 42 & $2.333(1.177-4.626)$ & 0.015 & 30 & $5.222(2.290-11.907)$ & $<0.001$ \\
\hline KLK1 $(\mathrm{ng} / \mathrm{ml})<25$ & 36 & 1 (ref.) & 47 & & & 14 & & \\
\hline$\geq 25$ & 28 & & 42 & $1.149(0.602-2.192)$ & 0.674 & 31 & $2.847(1.277-6.545)$ & 0.011 \\
\hline $\operatorname{AngII}(\mathrm{ng} / \mathrm{l})<186$ & 24 & 1 (ref.) & 53 & & & 19 & & \\
\hline$\geq 186$ & 41 & & 36 & $0.398(0.206-0.768)$ & 0.006 & 26 & $0.801(0.368-1.742)$ & 0.576 \\
\hline IL-6 (ng/l) <17 & 36 & 1 (ref.) & 47 & & & 14 & & \\
\hline$\geq 17$ & 28 & & 42 & $1.087(0.565-2.092)$ & 0.803 & 31 & $2.100(1.025-4.327)$ & 0.048 \\
\hline
\end{tabular}

Table 3. Associations between ACE I/D polymorphisms and the studied variables in STEMI patients. ACE: Angiotensin converting enzyme, KLK1: kallikrein, AngII: angiotensin II, IL-6: interleukin-6. On the basis of logistic regression, statistical significance $(\mathrm{p}<0.05)$ is shown in bold.

\begin{tabular}{|c|c|c|c|c|c|c|c|c|}
\hline \multirow{3}{*}{$\begin{array}{l}\text { ACE genotypes } \\
\text { Parameters }\end{array}$} & \multicolumn{2}{|c|}{ II $(n=65)$} & \multicolumn{3}{|c|}{ ID $(n=89)$} & \multicolumn{3}{|c|}{$\mathrm{DD}(\mathrm{n}=45)$} \\
\hline & \multirow[b]{2}{*}{$\mathbf{n}$} & & \multirow[b]{2}{*}{$\mathbf{n}$} & \multirow{2}{*}{\begin{tabular}{|l|} 
Multivariate \\
OR (95\% CI) \\
\end{tabular}} & \multirow[b]{2}{*}{$\mathbf{p}^{*}$} & \multirow[b]{2}{*}{ n } & \multirow{2}{*}{$\begin{array}{l}\text { Multivariate } \\
\text { OR (95\% CI) }\end{array}$} & \multirow[b]{2}{*}{$\mathbf{p}^{*}$} \\
\hline & & & & & & & & \\
\hline Smoking-No & 40 & 1 (ref.) & 33 & & & 17 & & \\
\hline Yes & 25 & & 56 & $3.204(1.557-6.595)$ & 0.020 & 28 & $3.204(1.557-6.595)$ & 0.003 \\
\hline $\operatorname{ACE}(\mathrm{ng} / \mathrm{ml})<174$ & 47 & 1 (ref.) & 47 & & & 15 & & \\
\hline$\geq 174$ & 18 & & 42 & $2.239(1.080-4.639)$ & 0.030 & 30 & $4.697(1.927-11.339)$ & 0.001 \\
\hline KLK1 (ng/ml) <25 & 36 & 1 (ref.) & 47 & & & 14 & & \\
\hline$\geq 25$ & 28 & & 42 & $1.046(0.987-1.109)$ & 0.130 & 31 & $3.339(1.383-8.063)$ & 0.007 \\
\hline
\end{tabular}

Table 4. The associations of ACE I/D polymorphisms with smoking habits and the studied variables in the multivariate logistic regression models. STEMI: ST segment elevation myocardial infarction, ACE: angiotensin converting enzyme, KLK1: kallikrein, CI: confidence interval; OR: odds ratio. The significant variables (smoking, ACE, KLK1) that demonstrated an independent association with ACE I/D polymorphism after multivariate logistic regression. The significant probability $(\mathrm{P})$ values $<0.05$ are given in bold.

Similar results were also found in a case-control study suggesting that subjects with the DD genotype had a 2.91-fold higher risk of STEMI than those with the II genotype ${ }^{23}$. Similar results were also widely indicated by other studies ${ }^{24}$. The effects of DD genotype of the ACE I/D polymorphism on plasma ACE levels and activity may be an important mechanism for the association of the ACE I/D polymorphism with the most urgent STEMI events $^{3}$. Our results suggest that STEMI patients with the ACE DD genotype showed the highest mean ACE plasma level, while patients with the ACE II genotype had the lowest mean plasma ACE level, in accordance with previous reports ${ }^{5}$.

Our present study revealed that the KLK1 plasma levels were higher in patients with STEMI carrying the D allele (ID/DD) compared to those lacking this allele (II). Although we have not obtained the exact mechanisms beyond this correlation, as we pointed out above and previous studies suggest that individuals with the $\mathrm{D}$ allele have significantly higher ACE plasma levels than do those with the I allele, which was validated by a substantial investigation ${ }^{2}$. The $47 \%$ phenotypic variance in ACE plasma levels was clarified by the ACE I/D gene polymorphism, and ACE plasma levels were $85 \%$ higher in DD subjects compared to II subjects, and ID subjects showed intermediate levels ${ }^{5}$. In addition, ACE is common to both RAS and KKS but plays different roles: it processes AngI to AngII and is the main BK-inactivating peptide ${ }^{25}$. KLK1 is the only member of the tissue KKS family that is responsible for the generation of BK. Subsequently, BK promotes vasodilation by the enhanced formation of nitric oxide $(\mathrm{NO})^{26}$. H. Buikema et al. demonstrated that the arteries from DD patients with a smaller capacity for NO release in response to stimulation ${ }^{27}$. Furthermore, Kakoki et al. proposed that the D allele was associated with rapid $\mathrm{BK}$ degradation as a result of higher levels and activity of $\mathrm{ACE}^{28}$. It is tempting to speculate that the high KLK1 levels observed in patients with the D allele may play an important compensatory role in their increased BK degradation.

Urata et al. first showed in vitro two pathways for the generation of AngII in human cardiac ventricles. A serine proteinase-dependent enzyme, which was identified as a new member of the chymase family, was responsible for approximately $80 \%$ of total AngII, while ACE-dependent AngII generation only accounted for $<11 \%$ of the AngII ${ }^{29}$. Despite the association of the D allele with increased levels of ACE, previous studies by varying degrees of ACEIs and computer simulations of the influence of genetically changing the levels of ACE revealed that such modest changes in ACE levels alter the levels of the substrate BK but had little effect on the active peptide AngII ${ }^{30}$. Furthermore, cellular studies stated that ACE has an even stronger affinity for BK than for AngI ${ }^{31}$. In the literature, we agree with the theory of Smithies that the decrease in the level of the active ACE substrate BK probably mediates the adverse effects of the $\mathrm{D}$ polymorphism but not the alteration in the level of AngII ${ }^{32}$. In the present study, we did not observe a difference in the level of active AngII regarding the ACE I/D polymorphism. 


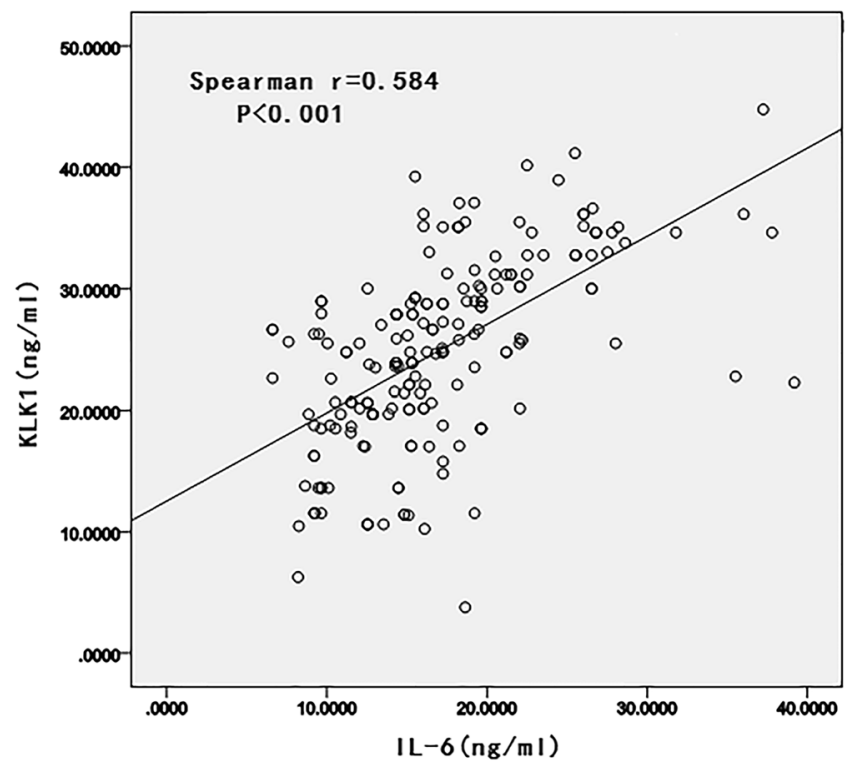

Figure 1. Scattered plot diagram showing the correlation between the levels of KLK1 and IL-6 among patients with STEMI.

STEMI primarily occurs due to rupture of atherosclerotic plaques. In this process, inflammation is thought to play a key role along with several other risk factors ${ }^{33}$. Previous investigations have shown that a high level of IL-6 is an independent predictor of adverse events in patients with $\mathrm{ACS}^{34}$. Our data showed that the presence of the D allele is related to higher IL-6, with $18.6 \mathrm{ng} / \mathrm{ml}$ in DD and $18.0 \mathrm{ng} / \mathrm{ml}$ in ID versus $14.7 \mathrm{ng} / \mathrm{ml}$ with the II genotype $^{15}$. As mentioned above, the results indicated that ACE DD has been reported to increase plasma ACE in accordance with previous studies. Increased ACE levels by the ACE I/D polymorphism may accelerate the expression of inflammatory cytokines, such as IL- 6 and IL- $8^{15,35}$.

In this study, we detected a significant positive correlation between plasma KLK1 levels and IL-6 levels in STEMI patients $(\mathrm{r}=0.584, \mathrm{P}<0.001)$. Previous studies have demonstrated that most of the biological functions of KLK1 are mediated by kinin receptor signaling, which can upregulate the expression of pro-inflammatory cytokines such as IL- 6 and IL- ${ }^{26}$. A recent study suggests that KLK1 may also activate protease-activated receptors (PARs), leading to intracellular $\mathrm{Ca} 2+$ mobilization and phosphorylation of MAPK signaling and subsequent cytokine production (IL-6, CCL-2, and IL-8) ${ }^{36}$. Additionally, both inflammation and angiogenesis correlate with vulnerable plaques ${ }^{37}$. KLK1 is highly expressed in unstable plaques, implying that KLK1 contributes to angiogenesis and is involved in inflammatory activation, leading to unstable plaque formation ${ }^{10}$. Clinical studies have shown that both elevated plasma IL-6 and KLK1 levels may increase plaque vulnerability and are associated with the severity of STEMI ${ }^{10,34}$. These reports provide evidence that supports the present findings.

Controversy surrounds the effect of the ACE I/D polymorphism on CAD and AMI ${ }^{38}$. Most subsequent studies have indicated no significant influence of this polymorphism on the extent of CAD but mainly on the onset of AMI, especially in STEMI. These data imply a possible mechanism involving plaque vulnerability, ulceration and thrombosis ${ }^{3}$. In this context, it is reasonable to hypothesize that alterations in ACE activity through the ACE I/D polymorphism may result in an increase in the expression levels of IL-6 and KLK1, which increases plaque vulnerability.

Study limitations. First, the results here are preliminary due to the limitation of the small number of patients. Second, it would be of interest in future animal and clinical studies to better confirm the mechanism of the association between the ACE I/D gene polymorphism and the level of ACE, IL-6, and KLK1, although we hypothesized that alterations in ACE activity through the ACE I/D polymorphism may result in an increase in the expression levels of these factors.

\section{Conclusion}

To our knowledge, this study is the first to show that high levels of ACE, KLK1 and IL-6 are detected when D allele is present, but AngII was not influenced by ACE I/D polymorphism.

\section{Data availability}

The dataset analyzed during the current study is available from the corresponding authors on reasonable request.

Received: 10 May 2019; Accepted: 9 December 2019;

Published online: 23 December 2019 


\section{References}

1. Dai, X., Wiernek, S., Evans, J. P. \& Runge, M. S. Genetics of coronary artery disease and myocardial infarction. World journal of cardiology 8, 1-23, https://doi.org/10.4330/wjc.v8.i1.1 (2016).

2. Cambien, F. et al. Plasma level and gene polymorphism of angiotensin-converting enzyme in relation to myocardial infarction. Circulation 90, 669-676 (1994).

3. Chen, Y., Dong, S., He, M., Qi, T. \& Zhu, W. Angiotensin-converting enzyme insertion/deletion polymorphism and risk of myocardial infarction in an updated meta-analysis based on 34993 participants. Gene 522, 196-205, https://doi.org/10.1016/j. gene.2013.03.076 (2013).

4. Dai, S. H. et al. Association of serum levels of AngII, KLK1, and ACE/KLK1 polymorphisms with acute myocardial infarction induced by coronary artery stenosis. Journal of the renin-angiotensin-aldosterone system: JRAAS 17, 1470320316655037, https://doi. org/10.1177/1470320316655037 (2016).

5. Rigat, B. et al. An insertion/deletion polymorphism in the angiotensin I-converting enzyme gene accounting for half the variance of serum enzyme levels. The Journal of clinical investigation 86, 1343-1346, https://doi.org/10.1172/JCI114844 (1990).

6. Takahashi, T. et al. Participation of reactive oxygen intermediates in the angiotensin II-activated signaling pathways in vascular smooth muscle cells. Annals of the New York Academy of Sciences 902, 283-287 (2000).

7. Shao, X. et al. Inducible expression of kallikrein in renal tubular cells protects mice against spontaneous lupus nephritis. Arthritis and rheumatism 65, 780-791, https://doi.org/10.1002/art.37798 (2013).

8. Fu, S. S. et al. Kallikrein gene-modified EPCs induce angiogenesis in rats with ischemic hindlimb and correlate with integrin alphavbeta3 expression. PloS one 8, e73035, https://doi.org/10.1371/journal.pone.0073035 (2013).

9. de Vries, M. R. \& Quax, P. H. Plaque angiogenesis and its relation to inflammation and atherosclerotic plaque destabilization. Current opinion in lipidology 27, 499-506, https://doi.org/10.1097/MOL.0000000000000339 (2016).

10. Yao, Y. Y. et al. Tissue kallikrein is related to the severity of coronary artery disease. Clinica chimica acta; international journal of clinical chemistry 423, 90-98, https://doi.org/10.1016/j.cca.2013.04.017 (2013).

11. Schieffer, B. et al. Expression of angiotensin II and interleukin 6 in human coronary atherosclerotic plaques: potential implications for inflammation and plaque instability. Circulation 101, 1372-1378 (2000).

12. Su, J. B. Different cross-talk sites between the renin-angiotensin and the kallikrein-kinin systems. Journal of the renin-angiotensinaldosterone system: JRAAS 15, 319-328, https://doi.org/10.1177/1470320312474854 (2014).

13. Tang, S. C. et al. Bradykinin and high glucose promote renal tubular inflammation. Nephrology, dialysis, transplantation: official publication of the European Dialysis and Transplant Association - European Renal Association 25, 698-710, https://doi.org/10.1093/ ndt/gfp599 (2010).

14. Fraga-Silva, R. A. et al. The angiotensin-converting enzyme 2/angiotensin-(1-7)/Mas receptor axis: a potential target for treating thrombotic diseases. Thrombosis and haemostasis 108, 1089-1096, https://doi.org/10.1160/TH12-06-0396 (2012).

15. Kortekaas, K. E. et al. ACE inhibitors potently reduce vascular inflammation, results of an open proof-of-concept study in the abdominal aortic aneurysm. PloS one 9, e111952, https://doi.org/10.1371/journal.pone.0111952 (2014).

16. The fundamental importance of smoking cessation in those with premature ST-segment elevation acute myocardial infarction.

17. Vaisi-Raygani, A. et al. The angiotensin converting enzyme D allele is an independent risk factor for early onset coronary artery disease. Clinical biochemistry 43, 1189-1194, https://doi.org/10.1016/j.clinbiochem.2010.07.010 (2010).

18. Parenica, J. et al. ACE gene insertion/deletion polymorphism has a mild influence on the acute development of left ventricular dysfunction in patients with ST elevation myocardial infarction treated with primary PCI. BMC cardiovascular disorders 10, 60, https://doi.org/10.1186/1471-2261-10-60 (2010).

19. Niemiec, P., Zak, I. \& Wita, K. Modification of the coronary artery disease risk associated with the presence of traditional risk factors by insertion/deletion polymorphism of the ACE gene. Genetic testing 11, 353-359, https://doi.org/10.1089/gte.2007.0005 (2007).

20. Drexler, H. \& Hornig, B. Endothelial dysfunction in human disease. Journal of molecular and cellular cardiology 31, 51-60, https:// doi.org/10.1006/jmcc.1998.0843 (1999).

21. Zhang, S., Day, I. \& Ye, S. Nicotine induced changes in gene expression by human coronary artery endothelial cells. Atherosclerosis 154, 277-283, https://doi.org/10.1016/s0021-9150(00)00475-5(2001).

22. Hibi, K. et al. Angiotensin-converting enzyme gene polymorphism adds risk for the severity of coronary atherosclerosis in smokers. Hypertension 30, 574-579, https://doi.org/10.1161/01.hyp.30.3.574 (1997).

23. Pulla Reddy, B. et al. Angiotensin-converting enzyme gene variant and its levels: risk factors for myocardial infarction in a South Indian population. Singapore medical journal 51, 576-581 (2010).

24. Mehri, S. et al. Angiotensin-converting enzyme insertion/deletion gene polymorphism in a Tunisian healthy and acute myocardial infarction population. Genetic testing and molecular biomarkers 14, 85-91, https://doi.org/10.1089/gtmb.2009.0105 (2010).

25. Rhaleb, N. E., Yang, X. P. \& Carretero, O. A. The kallikrein-kinin system as a regulator of cardiovascular and renal function. Comprehensive Physiology 1, 971-993, https://doi.org/10.1002/cphy.c100053 (2011).

26. Tang, S. C., Leung, J. C. \& Lai, K. N. The kallikrein-kinin system. Contributions to nephrology 170, 145-155, https://doi. org/10.1159/000325650 (2011).

27. Buikema, H. et al. The deletion polymorphism of the angiotensin-converting enzyme gene is related to phenotypic differences in human arteries. European heart journal 17, 787-794 (1996).

28. Kakoki, M. \& Smithies, O. The kallikrein-kinin system in health and in diseases of the kidney. Kidney international 75, 1019-1030, https://doi.org/10.1038/ki.2008.647 (2009).

29. Urata, H., Healy, B., Stewart, R. W., Bumpus, F. M. \& Husain, A. Angiotensin II-forming pathways in normal and failing human hearts. Circulation research 66, 883-890 (1990).

30. Campbell, D. J., Kladis, A. \& Duncan, A. M. Effects of converting enzyme inhibitors on angiotensin and bradykinin peptides. Hypertension 23, 439-449 (1994).

31. Sasaguri, M. et al. Purification and characterization of a kinin- and angiotensin II-forming enzyme in the dog heart. Journal of hypertension 15, 675-682 (1997).

32. Smithies, O., Kim, H. S., Takahashi, N. \& Edgell, M. H. Importance of quantitative genetic variations in the etiology of hypertension. Kidney Int 58, 2265-2280, https://doi.org/10.1046/j.1523-1755.2000.00411.x (2000).

33. Libby, P., Tabas, I., Fredman, G. \& Fisher, E. A. Inflammation and its resolution as determinants of acute coronary syndromes. Circulation research 114, 1867-1879, https://doi.org/10.1161/CIRCRESAHA.114.302699 (2014).

34. Garcia-Salas, J. M. et al. Interleukin-6 as a predictor of cardiovascular events in troponin-negative non-ST elevation acute coronary syndrome patients. International journal of clinical practice 68, 294-303, https://doi.org/10.1111/ijcp.12245 (2014).

35. Apavaloaie, M. C. et al. Inflammatory and Genetic Markers (APO B100 and Angiotensin-Converting Enzyme Gene) in the Coronary Artery Disease. Revista medico-chirurgicala a Societatii de Medici si Naturalisti din Iasi 120, 530-536 (2016).

36. Yiu, W. H. et al. Tissue kallikrein mediates pro-inflammatory pathways and activation of protease-activated receptor- 4 in proximal tubular epithelial cells. PloS one 9, e88894, https://doi.org/10.1371/journal.pone.0088894 (2014).

37. Davies, M. J. Stability and instability: two faces of coronary atherosclerosis. The Paul Dudley White Lecture 1995. Circulation 94 , 2013-2020 (1996).

38. Zintzaras, E., Raman, G., Kitsios, G. \& Lau, J. Angiotensin-converting enzyme insertion/deletion gene polymorphic variant as a marker of coronary artery disease: a meta-analysis. Archives of internal medicine 168, 1077-1089, https://doi.org/10.1001/ archinte.168.10.1077 (2008). 


\section{Author contributions}

Conceived and designed the experiments: S.H.D., L.Y.G., H.Y.L., M.D. and D.Q.L. Performed the experiments: S.H.D., L.Y.G., H.Y.L. and N.L. Analyzed the data: S.H.D., L.Y.G., H.Y.L., M.D., Z.L. and D.Q.L. Contributed reagents/materials/analysis tools: S.H.D., L.Y.G., H.Y.L., M.D., N.L., Z.L. and D.Q.L. Wrote the paper: S.H.D., L.Y.G., H.Y.L., M.D. and N.L.

\section{Competing interests}

The authors declare no competing interests.

\section{Additional information}

Correspondence and requests for materials should be addressed to L.G. or H.L.

Reprints and permissions information is available at www.nature.com/reprints.

Publisher's note Springer Nature remains neutral with regard to jurisdictional claims in published maps and institutional affiliations.

(c) (i) Open Access This article is licensed under a Creative Commons Attribution 4.0 International License, which permits use, sharing, adaptation, distribution and reproduction in any medium or format, as long as you give appropriate credit to the original author(s) and the source, provide a link to the Creative Commons license, and indicate if changes were made. The images or other third party material in this article are included in the article's Creative Commons license, unless indicated otherwise in a credit line to the material. If material is not included in the article's Creative Commons license and your intended use is not permitted by statutory regulation or exceeds the permitted use, you will need to obtain permission directly from the copyright holder. To view a copy of this license, visit http://creativecommons.org/licenses/by/4.0/.

(C) The Author(s) 2019 